Marquette University

e-Publications@Marquette

College of Nursing Faculty Research and

Publications

Nursing, College of

$5-1-2010$

Vision, Grit, and Collaboration: How the Wisconsin Center for Nursing Achieved Both Sustainable Funding and Established Itself as a State Health Care Workforce Leader

Lea Acord

Marquette University, lea.acord@marquette.edu

Gina Dennik-Champion

Wisconsin Nurses Association

Sally Peck Lundeen

University of Wisconsin - Milwaukee

Suzanne Schuler

Wisconsin Center for Nursing

Accepted version. Policy, Politics and Nursing Practice, Vol. 11, No. 2 (May 2010), DOI: 10.1177/

1527154410382146. (C) 2010 SAGE Publications. Used with permission. 


\title{
Vision, Grit, and Collaboration: How the Wisconsin Center for Nursing Achieved Both Sustainable Funding and Established Itself as a State Health Care Workforce Leader
}

\author{
Authors: Lea G. Acord, PhD, RN', Gina Dennik-Champion, MSN, MSHA, RN², Sally Peck \\ Lundeen, PhD, RN, FAAN ${ }^{3}$, and Suzanne G. Schuler, MSN, RN ${ }^{4}$
}

\begin{abstract}
In 2001, a dedicated group of nurses from across Wisconsin came together to discuss how to create a state center of expertise on key nursing workforce issues. The result was the establishment of the Wisconsin Center for Nursing (WCN) in 2005. Since that time, through its statewide Board of Directors, WCN has clarified and targeted specific state workforce needs and identified gaps that exist in addressing those needs. During its five-year existence, WCN has received funding from a variety of sources, and volunteers have spent hundreds of hours working on behalf of the organization. Finding a sustainable base of funding for WCN has been a priority in order to ensure that the organization can hire permanent staff and invest in ongoing initiatives. In 2009, WCN was involved in developing a strategy that resolved both the issue of sustainability and the need to collect and analyze data on the nursing profession. A bill was passed by the Wisconsin legislature that required $R N$ s and $L P N s$ to complete a comprehensive survey every two years when they renew their state licenses. In addition, the legislature raised the licensure fee for RNs and LPNs and dedicated a portion to WCN to assist in the analysis of the newly-collected nursing workforce data and to develop a state-wide plan addressing the future of the Wisconsin nursing workforce. This article will include the history of the WCN and the details of its journey toward sustainability including accomplishments and lessons learned.
\end{abstract}

In 2010, after nearly 10 years of work by a dedicated group of nurse leaders, the Wisconsin Center for Nursing (WCN) finally accomplished three significant goals.

- It drove the establishment of a systematic method for collecting and analyzing nurse workforce data;

- it achieved its long-sought objective of sustainable funding; and

- it cemented its reputation as an organization dedicated to creating an environment in which a variety of stakeholders-foundations, government entities, hospitals, nurses, and

1 Acord, Dennik-Champion, Peck Lundeen \& Schuler 
organizations representing a broad array of health care workers - can come together to ensure that a diverse and well-trained workforce will be able to meet the future health care needs of every community in Wisconsin.

The story of how WCN accomplished these goals demonstrates how vision, political savvy, determination and, finally, being in the right place at the right time, can lead to success. By describing our journey, we hope others will be able to learn from our experiences as they also strive to establish a well-functioning, highly respected and self-sustaining Center for Nursing in their state.

\section{Developing Innovative Partnerships}

In 2001, after several years of informal collaboration-and spurred by a growing concern about current and future nursing shortage projections - the chief nursing officers of the two largest integrated health systems in Wisconsin and the deans of the largest private and public colleges of nursing in the state set aside traditional competition to come together for a series of meetings to discuss strategies that could assure an adequate, well-prepared, and diverse nurse workforce to meet the needs of the citizens of Wisconsin.

This initial collaboration resulted in the establishment of the Wisconsin Nursing Redesign Consortium (WNRC) —an organization dedicated to developing a shared vision and increasing communication among nurses. The first day-long nursing leadership retreat organized by WNRC, scheduled for September 11, 2001, was interrupted by the announcement of the attack on the World Trade Center. That morning, more than 20 nursing leaders from across the state shared the experience of standing together watching the towers fall. Later, many of those present recall their increased resolve to work together to leave a positive statewide legacy for nursing despite having to cut short that initial meeting to return to their various institutions to deal with the chaos of the day.

During the next 4 years, WNRC focused on enhancing communication among nurses, increasing awareness of nursing workforce issues within the philanthropic and policy making communities, and leveraging nursing wisdom and power through innovative partnerships and collaboration.

The earliest and most committed partner of WNRC (and, to this day, of WCN) was the Faye McBeath Foundation, a private independent foundation providing grants to nonprofit organizations in the metropolitan Milwaukee area. The Foundation first established its

2 Acord, Dennik-Champion, Peck Lundeen \& Schuler 
relationship with the WNRC when it's then long-time Executive Director Sarah Dean-whose background included hospital administration — recognized WNRC's dedication to collaboration as a potential breakthrough strategy in health and nursing workforce management.

The first grant from the Foundation, awarded in December 2001, allowed WNRC to hire a part-time PhD nurse coordinator who played a critical role not only in writing additional grant applications but also in coordinating activities and communicating commitments among the volunteer nursing leaders who were doing the primary work of the organization.

The second US $\$ 50,000$ grant, awarded in February 2003, extended the Foundation's support of the mission of WRNC, in particular, the specific goal of developing a permanent Wisconsin Center for Nursing — something that had been in the group's strategic plan since 2001.

By then, under the leadership of a new Executive Director, the Faye McBeath Foundation provided a third grant of US\$100,000 to WNRC in December 2004. This time, however, the Foundation added a new requirement: receipt of one half of the award was contingent on a one-to-one match by other donors. In response to this challenge, every member of the WNRC steering committee, as well as nurses from across the state, contributed amounts ranging from a few dollars to US $\$ 1,000$. This investment by nurses themselves made a lasting impression on a wide array of constituencies and helped WNRC secure additional funding including a grant of US $\$ 50,000$ from the Wisconsin Hospital Association (WHA).

\section{Building Government Relationships}

Acutely aware that it could not survive on grants alone, during the early years WNRC sought funding from government agencies to establish a permanent Wisconsin Center for Nursing (WCN). This effort, however, was met with failure at every turn. Initially, WNRC was advised to seek 501 (c) (3) status but was later told that action might make attaining state funding more difficult. WNRC representatives then met with numerous legislators to seek support for the establishment of WCN but, in spite of assurances of commitment to the concept, funding was not forthcoming. At one point, they even worked with key legislators to draft legislation that paralleled the language used in other states to support a Center for Nursing, only to be eventually told that this option was not politically viable.

As early as 2003, it was even suggested that a Wisconsin Center for Nursing could be funded by an increase in the nurse licensing fees that were collected by the Department of Regulation and Licensing (DRL), the umbrella agency for all the health care professional licensing boards. Quickly, however, the DRL rejected the proposal as being not germane to the mission

3 Acord, Dennik-Champion, Peck Lundeen \& Schuler 
and purpose of the Department. WNRC also sought funding from the state Department of Workforce Development (DWD), but again was unsuccessful.

Despite this lack of financial support from the state, WNRC pursued a consistent strategy of building strong relationships with government agencies-relationships that were later to prove critical in the eventual funding of WCN. For example, in early 2002, the then-Governor created the Governor's Health Care Workforce Shortage Committee that focused on four main areas related to Wisconsin's health care workforce: (a) education; (b) retention and recruitment; (c) investment, resources, and infrastructure; and (d) workplace redesign. Representatives of WNRC as well as individuals representing nursing associations, nursing education, health care settings, labor, and government were members of the workgroups for this committee.

In mid-year 2002, the Governor released general recommendations that included the development of a leadership committee that would monitor the health care workforce shortage and serve as a catalyst for change. Unfortunately, this initiative was short-lived due to the election, later that year, of a new Governor. Soon, however, the new administration sought the help of the WNRC which had, by then, demonstrated its leadership in addressing nursing workforce issues.

In early 2003, the newly appointed Secretary of the Department of Workforce Development (DWD) created the Governor's Select Committee on Health Care Workforce Development, the purpose of which was to identify workforce issues related to meeting the health care needs of Wisconsin's citizens. This Committee again included nurse educators, health care organizations, and representatives from labor and government as well as from WNRC and the Wisconsin Nurses Association.

\section{Establishing a Track Record of Leadership}

During the period from 2001 through 2005, despite being chronically underfunded, the WNRC established itself, through sheer determination and the tireless efforts of a dedicated handful of volunteers, as a key statewide health care leadership organization. WNRC's first focus was to develop strong communication and collaboration among nursing leaders and policy makers across the state. To forward that goal, WNRC (and later WCN) sponsored five statewide conferences between 2001 and 2007 designed to share information among organizations and to define a nursing workforce redesign agenda.

- Other early accomplishments of WRNC were the following:

- Development and communication of a strategic plan;

4 Acord, Dennik-Champion, Peck Lundeen \& Schuler 
- development and dissemination of the "Wisconsin Nursing Community's Agenda for Health Care Reform" (developed in partnership with the Wisconsin Nursing Coalition and the Wisconsin Nurses Association);

- support of the development of several nursing practice redesign pilot projects;

- establishment of the Affiliation of Nurse Educators in Wisconsin (ANEW) - a unique statewide consortium of the deans and directors of all Wisconsin nursing education programs, including both baccalaureate and higher degree and technical school programs.

During this same period, two major Federal grant proposals, written by members of the WNRC Steering Committee, were also accepted and funded. The first, the Wisconsin Nurse Residency Program (awarded to Marquette University) received two 3-year cycles of funding from HRSA to implement a statewide support program for new nurse graduates.

The second, SWIFT—the State of Wisconsin Initiative to Fast Track Nurse Educators (awarded to the University of Wisconsin-Milwaukee) - provided US $\$ 1.3$ million in funding from the Department of Labor with a dollar-for-dollar match from health care employers. This program supported more than 60 nurses across the state in their efforts to complete master's degrees, based on their commitment to becoming nurse educators. Both initiatives used the collaborative, multisector, statewide approach established by the WNRC.

\section{Taking a Giant Leap of Faith}

After nearly 5 years of persistent attempts to find a state-funded revenue stream that would support the establishment of a Wisconsin Center for Nursing, the WNRC steering committee decided it was time to create WCN even though permanent funding was anything but certain. Their first priority was to establish WCN as a not-for-profit entity. So, early in 2006, with a volunteer retired nurse educator shepherding the process, WNRC filed papers to establish the Wisconsin Center for Nursing as a 501 (c) (3) organization. That same year, using continued funding from the Fay McBeath Foundation, WCN hired its first Executive Director and formed a new statewide Board of Directors.

Immediately, WCN continued in the tradition of its predecessor in establishing itself as a statewide health care policy leader. Among the accomplishments between 2006 and 2008 were the following:

5 Acord, Dennik-Champion, Peck Lundeen \& Schuler 
- The WCN President and Executive Director cochaired the Wisconsin Nurse Educator Task Force that was convened to assess issues and make recommendations related to the nurse educator shortage;

- WCN cosponsored, with the Select Committee of DWD, a Clinical Placement Summit to begin the process of coordinating clinical placements of students in nursing education programs in the greater Milwaukee area;

- Following in the tradition of WNRC, WCN held a fifth statewide conference. Entitled "Nurse Staffing and Patient Outcomes: Implications for Policy, Leadership and Research," the event was attended by more than 250 individuals.

Despite its track record of accomplishments, less than a year after it was established, WCN once again found itself without funding. Soon, however, creativity and a new partnership with a long-time supporter brought the organization back from the brink.

In 2007, the Robert Wood Johnson Foundation and the Northwest Health Foundation launched a national partnership-Partners Investing in Nursing (PIN) - to invest in nursing workforce and related strategies. This innovative concept contained a new twist: the funding application had to be submitted by a Foundation. Because of its long-standing relationship with the Faye McBeath Foundation, WCN convinced the Foundation to submit, for the first and only time in its 43-year history, a proposal for funding from another organization. Written collaboratively with WCN and entitled "Raising the Bar," the proposal requested funding to improve preparation, training, and placement of community and public health nurses in Wisconsin.

The fruits of years of capacity- and coalition-building by WNRC and WCN eventually led to the participation of nearly two dozen organizations in the PIN proposal including public health agencies, community nursing centers, and schools of nursing. The proposal eventually won 3 years of national funding and attracted two other local funding partners, the Greater Milwaukee Foundation and the Northwest Mutual Foundation, in addition to an US\$85,000 grant from the Faye McBeath Foundation itself.

Although the Faye McBeath Foundation was the grant recipient and a funder of the program, the lead administrative role was assumed by WCN. As a result, WCN was able to hire a half-time Executive Director, a part-time Project Director for the PIN grant, and administrative support.

In late 2008, a second opportunity presented itself as an avenue for additional short-term 6 Acord, Dennik-Champion, Peck Lundeen \& Schuler 
funding for WCN. As an acknowledged health workforce leader, WCN was a pivotal partner in a statewide collaborative with other health professions that wrote a grant proposal to obtain and analyze critical data about the state of the health professions in Wisconsin. In March 2009, the Wisconsin Health Workforce Data Collaborative (WHWDC) received a US $\$ 300,000$ 3-year grant from the Healthier Wisconsin Partnership Program through the Medical College of Wisconsin. The grant funded the collection of data for the purpose of statewide planning for the education of health care professionals. The data collection was to start with nurses-the largest health profession in Wisconsin - with the idea that the tools and processes developed for nurses would serve as a model for collecting data about other health professionals.

At the same time the WHWDC began developing its grant proposal, another important event took place that helped to shape the future of WCN. In May 2008, based on an application submitted by WCN, Wisconsin was invited as one of 18 states-out of a total of 48 applicants-to attend the Nursing Education Capacity Summit sponsored by the Center to Champion Nursing in America (CCNA). Funded by the Robert Wood Johnson Foundation, in cooperation with the AARP and the Department of Labor, the June 2008 Summit was convened to consult with experts, share best practices, and learn about innovative strategies to develop an action plan for nursing education. As a condition of its participation, WCN was expected to assemble a team of 10 attendees, each of whom would bring additional resources and provide unique perspectives at the Summit. The team, led by the WCN Executive Director, included a philanthropist, two nurse educators, the chair of the State Board of Nursing, staff from the state Department of Workforce Development, a Hospital Association representative, chief nursing officers from two large Wisconsin health care institutions, and a Wisconsin state senator who was also an RN.

Funding from the PIN grant and the Healthier Wisconsin grant provided a level of resource for WCN that finally allowed the Board to turn its attention to implementing the long-term plan to make WCN a self-sustaining organization. In addition, participation in the WHWDC and the CCNA Summit provided access to new resources, helped WCN establish valuable allies in key state departments, and created greater visibility with policy makers, leaders of other health care professions, funding sources, and government agencies.

\section{Desperately Seeking Data}

Throughout its history — and, indeed, for years before - the nurse leaders who were part of the Wisconsin Nursing Redesign Consortium and the subsequent Wisconsin Center for Nursing were frustrated by the lack of data regarding nurses and nursing practice in Wisconsin. In 1999,

7 Acord, Dennik-Champion, Peck Lundeen \& Schuler 
the Wisconsin Nursing Coalition (a quasi-formal group comprised of specialty nursing associations), nurse educators, nurse administrators, unions that represent nurses, state governmental agencies, WNA, and WHA spent 1 year examining the issues related to recruitment and retention of nurses in Wisconsin.

In 2000, Wisconsin's Bureau of Health Information met with members of the Coalition to discuss a nursing workforce survey. This resulted in a joint effort by hospitals, nursing homes, public health organizations, and the DWD and DRL to fund and distribute a 2001 RN Workforce Survey. The survey, which was mailed along with the nurse licensing renewal forms, achieved an impressive $63 \%$ response rate. Beyond an initial report of the data, however, no mechanism was established to make data collection and analysis an ongoing activity in the state and no organization was charged with using the data to make policy recommendations.

In 2004-as the 2001 survey results became increasingly out of date-WNRC representatives on the Select Committee on Health Care Workforce Development secured support for another nursing workforce survey. Led by WNA and WNRC, the voluntary survey this time achieved a participation rate of only $22 \%$. As a result, planners and decision makers in Wisconsin had to continue "flying blind" as they attempted to create proposed solutions to the state's nursing workforce challenges of the 21 st century.

In the summer of 2008 Senator Judy Robson, the nurse legislator who had been part of the team that attended the CCNA conference-convened a meeting of representatives from the DRL and DWD as well as WNA and WCN to discuss a potential legislative proposal to fund an ongoing nursing workforce survey and to designate an entity that could analyze and disseminate the data and support the development of long-term statewide plans and strategies.

Simultaneously, the Wisconsin Hospital Association (WHA) convinced the members of a Legislative Council Study Committee on Wisconsin Workforce to support workforce surveys related to all the health care professions.

From these two activities, a legislative proposal emerged that called for the DRL to work with the DWD to conduct workforce surveys, starting with a survey of RNs in 2010 and LPNs in 2011. Legislation to that effect was ultimately introduced by Senator Robson.

\section{Bringing it All Together}

The stage was set. WCN had established itself as a credible and professional organization with expertise in nursing workforce matters and-based on member participation in the CCNA Conference and the Wisconsin Health Workforce Data Collaborative-a reliable partner in the

8 Acord, Dennik-Champion, Peck Lundeen \& Schuler 
collection and analysis of workforce data for all the health care professions in the state.

At the same time, Senator Robson, partly as a result of her extensive interaction with WCN, WNA, and WHA had developed an increased appreciation of the critical need for information and analysis to ensure that the state is able to meet its future health care needs. All that was needed was to find a way to establish WCN as the entity charged with working with DWD to analyze and disseminate the data and then fund both WCN's role and the survey on an ongoing basis.

The unexpected answer came in the form of an announcement by the Governor that he planned to raise state license fees across the board as a part of his 2009-2011 Biennial Budget. The concern that an increase in nurse license fees would be construed as a "new tax" had stymied this strategy as a source of funding for nearly 5 years. Since the license fees were going to increase anyway, however, a proposal was made to add an additional amount (US\$2 per year) to each nurse license fee to fund the collection, analysis, and dissemination of nurse workforce data.

To accomplish this part of the plan, advocates had to convince the Joint Finance Committee of the state legislature - whose recommendations usually become law as part of the final state budgeting process - that this idea was viable. So, WCN representatives and others testified at public Joint Finance Committee hearings throughout the state. The Executive Director for WNA also served as the liaison between WCN and the nurse state senator on the legislative language and actively lobbied the cochairs of the Joint Finance Committee.

After extended negotiation-and some last-minute concerns expressed by the DRL-two pieces of legislation were passed. In June 2009, a bill was signed into law that mandated that the DRL collect data on RNs and LPNs as a condition of their biennial license renewal. At the same time, final language in the 2009-2011 state budget stipulated that a US $\$ 4$ biennial fee per RN and LPN license renewal would be used to fund both the data collection and the work of a "coordinating entity" charged with analyzing and disseminating that data.

Specifically, the legislation directed the DRL to administer the survey and collect the fees, then transfer a designated portion to the DWD that would serve as the governmental agency charged with funding the coordinating entity (WCN). WCN in turn would work with DWD to analyze the data and, among other things, facilitate partnerships between the nursing community and other health care providers, the licensing authority, business and industry, consumers, legislators, and educators to achieve policy consensus, promote diversity within the profession, and enhance nursing career mobility and nursing leadership development.

\section{Delivering on the Promise}

9 Acord, Dennik-Champion, Peck Lundeen \& Schuler 
Although it would not see funding for another 8 to 9 months, in July 2009 WCN had a clear mandate to work with the DWD to draft a valid and meaningful online survey that would be launched in January 2010 when approximately 77,500 RNs had to renew their licenses.

Fortunately, its participation in CCNA had already given WCN the opportunity to collaborate with other state centers for nursing to create standardized questions and data requirements.

Because states differ substantially in the questions they ask and the methods and metrics they use to collect nurse workforce data, it is difficult to compare data from state to state as well as create a complete national picture of nursing. So in 2008, CCNA partially funded a project by the Florida Center for Nursing to work with the Forum of State Nursing Workforce Centers to create three national nursing workforce minimum data sets: (a) a nurse-supply dataset, (b) a nurse-demand dataset and (c) a nursing-education dataset. WCN had the opportunity to both contribute to the development of these datasets and eventually to use the supply data-set as a foundation for Wisconsin's survey.

The launch in January 2010 of the mandatory RN workforce survey marked the culmination of a successful collaboration between the state's regulatory and workforce agencies, WCN, and many other organizations. With very little fanfare or complaint, more than 70,000 nurses filled out the online survey and approximately 5,000 nurses requested and completed a paper copy. The resulting data will allow WCN to create information that will help professional organizations and policy makers predict supply and forecast demand for nurses in Wisconsin. The incorporation of all the questions from the national minimum nurse supply dataset will also allow Wisconsin to compare its data with other states.

As of the writing of this article, the WCN leadership is anxiously awaiting the first data from the survey as well as the first major influx of funding from DWD. In anticipation of both events, however, WCN has launched a search for a new full-time Executive Director and has named two respected nurse educators as cochairs of a Data Subcommittee charged with developing a plan to analyze and use the data. Plans are also being developed to reach out to nurse researchers across the state to involve them in ensuring that the analysis techniques are state-of-the-art and that the conclusions are valid and well tested.

Building on the foundation of many years of work, not only of nurse leaders and other organizations but also on the generosity of foundations and individuals, WCN has now reached a stage where it is poised to play the pivotal role imagined for the organization when, 8 years earlier, WNRC developed the following vision: Wisconsin will have a diverse nurse workforce, sufficient in number, appropriately educated, effectively utilized and adequately supported to provide safe and

\section{Acord, Dennik-Champion, Peck Lundeen \& Schuler}


quality evidence-based care that improves health outcomes of Wisconsin residents.

\section{Lessons Learned}

It is hoped that, in describing our journey, many of the lessons we learned along the way will be obvious but, to recap, we offer the following precepts that may be helpful to others looking to take a similar journey.

\section{Collaboration is everything}

If we had not been willing to reach out to partner wherever we could, we never would have had the opportunities to develop the expertise and relationships that ended up serving us so well.

\section{Volunteers can only do so much}

Based on foundation funding as well as some very creative partnerships with local universities and other organizations, WCN was able to hire key administrative and executive support at critical times in the organization's history. Even if funding isn't sure or continuous, make hiring at least a core staff member a priority.

\section{Be visible in many sectors}

If WNRC and WCN hadn't been committed to creating programs and opportunities from the very beginning, we would not have been in the places, and connected to critical organizations, to achieve ultimate funding and recognition. The Wisconsin Center for Nursing and WNRC took advantage of many opportunities to assert leadership in the state.

\section{Be nimble when opportunities present themselves}

When the Governor made a decision to increase licensing fees, for instance, WCN had very little time to react but we did so quickly, using the relationships and skills we had already developed.

\section{Maintain leadership continuity}

Many of the leaders who came together in 2001-and some who had been working on these issues far longer-continue to serve in key roles today at WCN. This long-term commitment and leadership continuity has made all the difference when funding made it hard to maintain a similar continuity in paid staff.

\section{Reach out to other health care professions}

Nursing is not the only health care profession that needs to plan for a sustainable and well-trained workforce. Working with others in health care will not only provide needed allies and expertise but will also establish nurses as appropriate leaders in helping to solve strategic health care issues.

11 Acord, Dennik-Champion, Peck Lundeen \& Schuler 


\section{Be creative in funding}

To stay afloat, WCN and WNRC had to be very creative in the use of everything from in-kind facilities and services to donations from volunteers. Tapping volunteers to support the organization when there are no other options can also strengthen the loyalty of the volunteers and show others the depth of your commitment as an organization.

\section{Develop strong relationships with foundations focused on health care issues}

There are many foundations, including strong local ones like the Faye McBeath

Foundation, which can not only be funding sources but also sources of information, expertise, and support.

\section{Seek out free support and advice}

WCN was able to tap many sources of information and expertise including other nonprofits, other state centers for nursing, government committees, and foundations. We also took full advantage of our strong statewide advisory board.

\section{Keep your eyes on the prize and be tenacious}

Develop a long-term vision and keep moving toward your goals, even when things look bleak.

\section{Notes}

${ }^{1}$ Marquette University, Milwaukee, WI

${ }^{2}$ Wisconsin Nurses Association, Monona, WI

${ }^{3}$ University of Wisconsin-Milwaukee College of Nursing

${ }^{4}$ Wisconsin Center for Nursing, Milwaukee

\section{Corresponding Author:}

Lea G. Acord, Professor, College of Nursing, Marquette University, PO Box 1881, Milwaukee, WI 53201 Email: lea.acord@marquette.edu

\section{Declaration of Conflicting Interests}

The author(s) declared no potential conflicts of interest with respect to the authorship and/or publication of this article.

\section{Funding}

The author(s) received no financial support for the research and/or authorship of this article.

\section{Bios}

Lea G. Acord is professor at Marquette University (MU) and former dean of the MU College of Nursing from 2003 to 2007. She was involved in the early stages of WNRC and helped drive the 12 Acord, Dennik-Champion, Peck Lundeen \& Schuler 
establishment of WCN. She served as executive director of WCN from 2007 to 2009 and currently serves as an advisory board member of WCN.

Gina Dennik-Champion is the executive director of the Wisconsin Nurses Association (WNA). In this position, she worked on behalf of WNA to support the establishment and state funding of WCN. She has also been involved in the development of all three nursing workforce surveys in the state.

Sally Peck Lundeen is dean and professor at the University of Wisconsin-Milwaukee College of Nursing. One of the founders of the WNRC, she was also the principle investigator on the State of Wisconsin Initiative to Fast Track (SWIFT) Nurses Educators grant. She was the first president of the WCN Board of Directors.

Suzanne G. Schuler is the current interim executive director of WCN. She served as the public policy leader for WNRC and was the first vice president of the WCN Board of Directors. She also served as president of the WCN Board from 2008 to 2010.

13 Acord, Dennik-Champion, Peck Lundeen \& Schuler 